\title{
Short Communication Modification of second cancer risk after malignant melanoma by parental history of cancer
}

\author{
H Zhang', J Lorenzo Bermejo*,', J Sundquist ${ }^{2}$ and K Hemminki ${ }^{1,2}$ \\ 'Division of Molecular Genetic Epidemiology, German Cancer Research Center (DKFZ), Heidelberg, Germany; ${ }^{2}$ Center for Family and Community \\ Medicine, Karolinska Institute, Alfred Nobels alle 12, 14183 Huddinge, Sweden
}

The Swedish Family-Cancer Database was used to quantify the incidence of second tumours in melanoma patients with a parental history of cancer. Patients with parents affected by melanoma showed a 32.3-fold risk of second primary melanomas, which was greater than a multiplicative interaction.

British Journal of Cancer (2008) 99, 536-538. doi:I0.1038/sj.bjc.6604489 www.bjcancer.com

Published online 15 July 2008

(c) 2008 Cancer Research UK

Keywords: familial risk; second cancer; genetic susceptibility; melanoma

Compared with other skin cancers, cutaneous melanoma $(\mathrm{CM})$ is a rare disease, with an incidence rate of 14 cases per 100000 in Sweden, one of the highest rates in Europe (de Vries and Coebergh, 2004). In contrast, CM is responsible for $80 \%$ of all skin cancerrelated deaths (Miller and Mihm, 2006). The improvements in survival after melanoma have resulted in an increased incidence of subsequent primary tumour survival (Bhatia et al, 1999). Melanoma patients are prone to develop second tumours in the breast, prostate, kidney and skin, and particularly, second primary melanomas (Schmid-Wendtner et al, 2001; Goggins and Tsao, 2003), but those with a parental history of cancer have not been ascertained separately. The present population-based study investigates the risk of type-specific second tumours after diagnosis of melanoma and expands on the familial risk of subsequent cancers. Apart from its importance for clinical counselling and prevention, an understanding of the role of parental history in multiple cancers may help to understand cancer aetiology.

\section{MATERIALS AND METHODS}

The Swedish Family-Cancer Database, which was created in 1995 and last updated in 2006, includes a total of 11.5 million individuals. The Database covers offspring born or immigrated after 1931 with information on biological parents (Hemminki et al, 2006). In this study, cancers were classified according to the 4-digit diagnostic code from the seventh version of the International Classification of Disease (ICD-7). Tumours are compulsorily reported in Sweden and the agreement between clinical and cytological or histological diagnoses is close to $100 \%$.

In the present retrospective cohort study, follow-up started at diagnosis of melanoma in a member of the offspring generation and it ended at occurrence of death, emigration, the diagnosis of any subsequent malignancy or 31 December 2004 (close date of the

*Correspondence: Dr J Lorenzo Bermejo; E-mail: J.lorenzo@dkfz.de Received 15 May 2008; revised 9 June 2008; accepted 9 June 2008; published online 15 July 2008 study). Two types of parental history were investigated: a parental history of melanoma (one of the two parents of the individual diagnosed with malignant melanoma) and a concordant parental history (one of the parents affected by the same type of cancer as the second primary cancer in the offspring). Standardized incidence ratios (SIR) were used to measure the relative risk of second cancers and they were calculated as the ratio of observed (O) to expected (E) number of cases. The expected numbers were computed from the first primary cancer incidence rates taking into account age (5-year intervals), region (four regions), calendar period (1960-1964, 1965-1969,.., 2000-2004) and socio-economic status (six groups). A Poisson distribution of the number of cases was assumed. Multiplicative interaction indexes (MIIs) and interaction contrast ratios (ICRs) were used to investigate the possible interaction between 'individual history of melanoma' and 'parental history of cancer'. If $\mathrm{SIR}_{\text {melanoma }}$ represents the relative risk of cancer after melanoma, $\mathrm{SIR}_{\mathrm{ph}}$ the relative risk in individuals with a parental history of cancer and SIR melanomaxph the relative risk in melanoma patients with a parental history, $\mathrm{MII}=$ $\mathrm{SIR}_{\text {melanomaxph }} /\left(\mathrm{SIR}_{\text {melanoma }} \mathrm{xSIR} \mathrm{ph}_{\mathrm{ph}}\right)$ and $\mathrm{ICR}=\mathrm{SIR}_{\text {melanomaxfh }}{ }^{-}$ $\mathrm{SIR}_{\text {melanoma }}-\mathrm{SIR}_{\mathrm{ph}}+1$. MII1 suggests departure from multiplicativity and ICR0 indicates departure from additivity. Confidence intervals and $P$-values for MII and ICR were calculated by bootstrapping using 10000 replications. All statistical analyses were carried out in SAS 9.1.

\section{RESULTS}

We identified 15581 individuals in the offspring generation diagnosed with malignant melanoma before the age of 73 years (registration of individuals started in 1931 and the last update of the Database includes cancers diagnosed before year 2004). Among the patients, 1156 developed a subsequent cancer. Table 1 shows the SIRs for sites where at least 10 cases were observed. Compared with the general Swedish population, an increased risk of second cancer was observed for the breast (1.35), prostate (1.22), skin (melanoma 9.03 and squamous cell 3.48) and nervous system (1.66). Lymphohematopoietic neoplasms were also in excess, 
Table I Relative risks of second neoplasms after melanoma in the general population and in patients with a parental history of melanoma

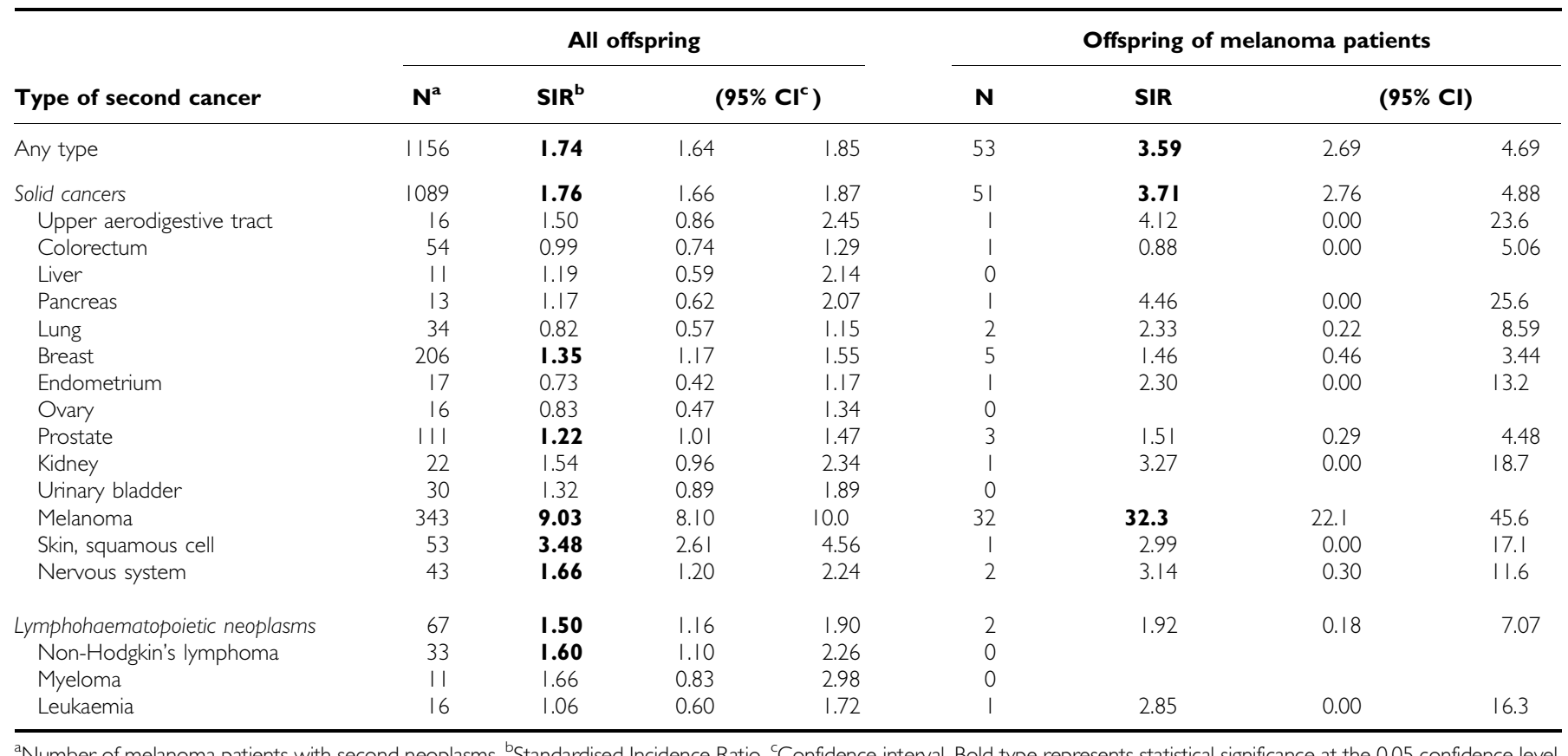

Table 2 Parental relative risks of cancer and relative risks of second neoplasms in melanoma patients with a parental history of concordant (same site) cancer

\begin{tabular}{|c|c|c|c|c|c|c|c|c|}
\hline \multirow{3}{*}{$\begin{array}{l}\text { Type of second cancer } \\
\text { Any type }\end{array}$} & \multicolumn{4}{|c|}{$\begin{array}{l}\text { Individuals with parents affected } \\
\text { by concordant cancer }\end{array}$} & \multicolumn{4}{|c|}{$\begin{array}{l}\text { Melanoma patients with parents affected } \\
\text { by concordant cancer }\end{array}$} \\
\hline & \multirow{2}{*}{$\frac{\mathbf{N}^{\mathbf{a}}}{81548}$} & \multirow{2}{*}{$\begin{array}{l}\text { SIR }^{\mathbf{b}} \\
\mathbf{I . 0 5}\end{array}$} & \multicolumn{2}{|c|}{$\left(95 \% \mathrm{Cl}^{\mathrm{c}}\right)$} & \multirow{2}{*}{$\frac{\mathbf{N}}{629}$} & \multirow{2}{*}{$\begin{array}{l}\text { SIR } \\
1.93\end{array}$} & \multicolumn{2}{|c|}{$(95 \% \mathrm{Cl})$} \\
\hline & & & 1.05 & 1.06 & & & 1.78 & 2.09 \\
\hline Solid cancers & 71104 & 1.06 & 1.05 & 1.07 & 557 & 1.95 & 1.79 & 2.12 \\
\hline Upper aerodigestive tract & 49 & 1.67 & 1.26 & 2.22 & 0 & & & \\
\hline Colorectum & 1573 & 1.69 & $|.6|$ & 1.78 & 3 & 0.76 & 0.14 & 2.25 \\
\hline Liver & 60 & 1.30 & 1.01 & 1.69 & 2 & 13.5 & 1.28 & 49.8 \\
\hline Pancreas & 85 & 2.01 & 1.62 & 2.50 & 1 & 4.82 & 0.00 & 27.7 \\
\hline Lung & 647 & 1.72 & 1.58 & 1.86 & I & 0.56 & 0.00 & 3.20 \\
\hline Breast & 3656 & 1.64 & 1.59 & 1.70 & 25 & 2.51 & 1.62 & 3.71 \\
\hline Endometrium & 163 & 2.16 & 1.85 & 2.52 & I & 3.07 & 0.00 & 17.6 \\
\hline Ovary & 176 & 2.48 & 2.13 & 2.88 & 0 & & & \\
\hline Prostate & 2472 & 1.88 & 1.80 & 1.96 & || & 1.57 & 0.78 & 2.82 \\
\hline Kidney & 119 & 2.19 & 1.82 & 2.62 & 3 & 13.1 & 2.47 & 38.7 \\
\hline Urinary bladder & 279 & 1.79 & 1.58 & 2.01 & 2 & 3.25 & 0.31 & 12.0 \\
\hline Melanoma & 438 & 2.44 & 2.22 & 2.68 & 32 & 32.3 & 22.1 & 45.6 \\
\hline Skin, squamous cell & 172 & 2.03 & 1.74 & 2.36 & 2 & 4.04 & 0.38 & 14.8 \\
\hline Nervous system & 257 & 1.69 & 1.50 & 1.92 & 1 & 2.23 & 0.00 & 12.8 \\
\hline Lymphohaematopoietic neoplasms & 879 & 1.38 & 1.29 & 5 & 2.83 & 0.89 & & 6.65 \\
\hline Non-Hodgkin's lymphoma & 167 & 1.86 & 1.60 & 2.17 & 2 & 6.33 & 0.60 & 23.3 \\
\hline Myeloma & 35 & 2.43 & 1.74 & 3.40 & 0 & & & \\
\hline Leukaemia & 150 & 1.87 & 1.58 & 2.19 & I & 4.47 & 0.00 & 25.7 \\
\hline
\end{tabular}

${ }^{a}$ Number of cases with a parental history. ${ }^{b}$ Standardised Incidence Ratio. ${ }^{c}$ Confidence interval. Bold type represents statistical significance at the 0.05 confidence level.

mostly because of an increased risk of non-Hodgkin's lymphoma with an SIR of 1.60. A parental history of melanoma increased the risk of second melanoma to an SIR of 32.3. The analysis of the interaction between individual and parental history of melanoma resulted in $\mathrm{MII}=1.46(95 \% \mathrm{CI} 1.06$ to $2.03, P=0.03)$ and $\mathrm{ICR}=21.7(95 \%$ CI $13.3-33.3, P<0.01)$, thus suggesting greater than multiplicative and greater than additive interaction effects.

Table 2 shows the relative risks of site-specific cancers for individuals with a parental family history of the particular cancer (first column) and the parental risks of the same (concordant) cancer after melanoma. For example, the relative risk of liver cancer was 1.3 for the offspring of liver cancer patients, but the SIR increased to 13.5 (two cases) when the offspring were melanoma patients. The relative risk of breast cancer in women with affected mothers was 1.64 , and it increased to 2.51 among melanoma patients with a maternal history of breast cancer. The interaction between 'individual history of melanoma' and 'maternal history of breast cancer' did not significantly depart from multiplicativity or additivity $(\mathrm{MII}=1.13(95 \% \mathrm{CI} 0.79-1.64, P=0.29)$ and $\mathrm{ICR}=0.52$ (95\% CI $-0.24-1.59, P=1.14)$ ). Melanoma patients with a 
parental history of kidney cancer were at very high risk of developing second kidney cancers (SIR 13.1, three cases).

\section{DISCUSSION}

The present study, based on the nation-wide Swedish FamilyCancer Database, focuses on the risk of subsequent cancer after malignant melanoma in individuals with a parental history of cancer. In agreement with previous studies, melanoma patients were at an increased risk of second tumours, including melanomas and lymphomas. The reasons for these increases are probably manifold. Immune suppression induced by therapy, exposure to ultraviolet radiation and the primary disease could explain some cases, particularly for non-Hodgkin's lymphoma (Ebbesen, 1981; Romedahl et al, 1988; Hemminki et al, 2003). A novel result of this study was the increased risk observed for squamous cell carcinoma. This association has been previously observed in a reversed sequence: increased risk of melanoma after squamous cell carcinoma (Hemminki and Dong, 2000). In addition to treatmentrelated factors, unidentified susceptibility genes could explain these results to some extent. Inactivation of CDKN2A by genetic and epigenetic changes has been described in melanoma, squamous cell carcinoma, breast cancer and Hodgkin disease (Soufir et al, 1999; Brown et al, 2004; Debniak et al, 2007; Sinha et al, 2008). However, the association between germline mutations in CDKN2A and malignancies other than melanoma are still unclear. Mutations in MC1R, a low-penetrance melanoma-predisposing gene, could also be involved in squamous cell skin cancers

\section{REFERENCES}

Bhatia S, Estrada-Batres L, Maryon T, Bogue M, Chu D (1999) Second primary tumors in patients with cutaneous malignant melanoma. Cancer 86: $2014-2020$

Box NF, Duffy DL, Irving RE, Russell A, Chen W, Griffyths LR, Parsons PG, Green AC, Sturm RA (2001) Melanocortin-1 receptor genotype is a risk factor for basal and squamous cell carcinoma. J Invest Dermatol 116: 224-229

Brown VL, Harwood CV, Crook T, Cronin JG, Kelsell DR, Proby CM (2004) p16INK4a and p14ARF tumor suppressor genes are commonly inactivated in cutaneous squamous cell carcinoma. J Invest Dermatol 122: 1284-1292

Debniak T, Cybulski C, Górski B, Huzarski T, Byrski T, Gronwald J, Jakubowska A, Kowalska E, Oszurek O, Narod SA, Lubiński J (2007) CDKN2A-positive breast cancers in young women from Poland. Breast Cancer Res Treat 103: 355-359

de Vries E, Coebergh JW (2004) Cutaneous malignant melanoma in Europe. Eur J Cancer 40: 2355-2366

Ebbesen P (1981) Enhanced lymphoma incidence in BALB/c mice after ultraviolet treatment. J Natl Cancer Inst 67: 1077-1078

Figl A, Thirumaran RK, Ugurel S, Gast A, Hemminki K, Kumar R, Schadendorf D (2007) Multiple melanomas after treatment for Hodgkin lymphoma in a non-Dutch p16-Leiden mutation carrier with $2 \mathrm{MC1R}$ high-risk variants. Arch Dermatol 143: 495-499

Goggins WB, Tsao H (2003) A population-based analysis of risk factors for a second primary cutaneous melanoma among melanoma Survivors. Cancer 97: 639-643

Hemminki K, Vaittinen P (1997) Interaction of breast cancer and melanoma genotypes. Lancet 350: 931-932 and in Hodgkin's disease (Palmer et al, 2000; Box et al, 2001; Figl et al, 2007). The novel data from the present study refer to the risk of second concordant tumours in melanoma patients with a parental history of cancer. The risks were increased for second liver and kidney cancers after melanoma when the parents were diagnosed with liver or kidney cancer, respectively; however, the number of cases was small. More convincingly, a greater than additive and greater than multiplicative interaction was observed between parental and individual history of melanoma, with an expected SIR of $2.44 \times 8.41=20.5$ and an observed SIR of 32.3 (the SIR of second melanoma for individuals without a parental history was $8.41,311$ cases, $95 \%$ confidence interval: $7.50-9.40$, data not shown). A study based on a previous version of the Database showed that, when mothers had breast cancer and fathers melanoma, the offspring was at a high risk of both breast cancer and melanoma (Hemminki and Vaittinen, 1997). The present data could mirror the effects of gene-environment interactions - for example, between CDKN2A mutations and UV-exposure - or the combinations among yet unidentified susceptibility genes.

\section{ACKNOWLEDGEMENTS}

This study was supported by Deutsche Krebshilfe, the Swedish Cancer Society, the EU, LSHC-CT-2004-503465 and the Swedish Council for Working Life and Social Research. The Family-Cancer Database was created by linking registers maintained at Statistics Sweden and the Swedish Cancer Registry.
Hemminki K, Dong C (2000) Subsequent cancers after in situ and invasive squamous cell carcinoma of the skin. Arch Dermatol 136: 647-651

Hemminki K, Jiang Y, Steineck G (2003) Skin cancer and non-Hodgkin's lymphoma as second malignancies, markers of impaired immune function? Eur J Cancer 39: 223-229

Hemminki K, Granström C, Sundquist J, Lorenzo Bermejo J (2006) The updated Swedish family-cancer database used to assess familial risks of prostate cancer during rapidly increasing incidence. Heredit Cancer in Clin Pract 4: 186-192

Miller AJ, Mihm Jr MC (2006) Melanoma. $N$ Engl J Med 355: 51-65

Palmer JS, Duffy DL, Box NF, Aitken JF, O'Gorman LE, Green AC, Hayward NK, Martin NG, Sturm RA (2000) Melanocortin-1 receptor polymorphisms and risk of melanoma: is the association explained solely by pigmentation phenotype? Am J Hum Genet 66: 176-186

Romedahl CA, Donawho C, Fidler IJ, Kripke ML (1988) Effect of ultraviolet$B$ radiation on the in vivo growth of murine melanoma cells. Cancer Res 48: $4007-4010$

Schmid-Wendtner M-H, Baumert J, Wendtner C-M, Plewig G, Volkenandt $M$ (2001) Risk of second primary malignancies in patients with cutaneous melanoma. Br J Dermatol 145: $981-985$

Sinha S, Chunder N, Mukherjee N, Alam N, Roy A, Roychoudhury S, Kumar Panda C (2008) Frequent deletion and methylation in SH3GL2 and CDKN2A loci are associated with early- and late-onset breast carcinoma. Ann Surg Oncol 15(4): 1070-1080

Soufir N, Molès JP, Vilmer C, Moch C, Verola O, Rivet J, Tesniere A, Dubertret L, Basset-Seguin N (1999) P16 UV mutations in human skin epithelial tumors. Oncogene 18: 5477-5481 